\title{
Preoperative evaluation of a surgical patient; preanesthetic interview by anesthesiology residents
}

\author{
Jae Hwan Kim \\ Department of Anesthesiology and Pain Medicine, Korea University College of Medicine, Seoul, Korea
}

The preoperative evaluation of a surgical patient by an anesthesiologist is an important interaction between the patient and physician. This process allows the anesthesiologist to carefully assess the patient's medical condition, evaluate the patient's overall health status, determine risk factors against the anesthesia, educate the patient, discuss the procedure of anesthesia and options for postoperative control, and obtain informed consent. During preoperative evaluation, the patient can gain a realistic understanding of the proposed anesthesia and realize the possible complications during the perioperative period. Any problem that is identified during this evaluation may also be addressed prior to surgery, or, if necessary, surgery may be delayed on rare occasions.

The time invested in a preoperative evaluation yields an improved relationship between anesthesiologist and patient and reduces anesthetic complications. This preoperative evaluation of a surgical patient is done at the preoperative evaluation clinic. Also, for patients who are already admitted to the hospital, the preoperative interview can be done in their room. This preoperative evaluation and interview is the first introduction of anesthesia to the patient. Egbert et al. [1] reported that the preoperative interview was shown to reduce patient anxiety before surgery and may even decrease postoperative pain and length of hospital stay. This may be due to the patient's perceived control over the expected perioperative events he/she will be experiencing. Also, an effective preanesthetic interview is increasingly recognized to influence a variety of patient behaviors such as patient's satisfaction and understanding of medical advice [2]. This preoperative evaluation and interview is vital to establishing a relationship between anesthesiologist and patient, and remains a fundamental part of the anesthesiologist's practice.

In the current issue of the Korean Journal of Anesthesiology [3], the authors studied the effects of a preanesthetic interview that was conducted by anesthesiology residents and the authors evaluated it. They reported that the duration of the preanesthetic interview was $184 \mathrm{sec}$ including $8 \mathrm{sec}$ of greeting, $45 \mathrm{sec}$ of history taking, $15 \mathrm{sec}$ of physical examination, 50 sec of getting an informed consent, $20 \mathrm{sec}$ of explanation for anesthetic planning, $15 \mathrm{sec}$ of explanation for patient controlled analgesia, and $10 \mathrm{sec}$ of question and answer. They said that age, American Society of Anesthesiologists physical status classification, and education level correlate with the duration of the preanesthetic interview. Their patient's satisfaction rate was $89 \%$. However the anxiety level of their patients was decreased in $50 \%$, not changed in $42 \%$, and increased in $8 \%$ of patients.

Training of the resident in communication skills is required to understand the physiological changes of the patient associated with surgery and anesthesia. Harms et al. [4] reported that communication skills training reduces the patient's anxiety and improves the patient's satisfaction. They emphasized the communication skill training program in the anesthesiology residency. However, nearly $50 \%$ of hospitals did not teach interview skills to their residents [5]. If we have a more sophisticated residency program for the communication skill, we could have more positive results in the preoperative interview.

Nowadays there is an increasing trend toward shorter times

Corresponding author: Jae Hwan Kim, M.D., Department of Anesthesiology and Pain Medicine, Korea University Ansan Hospital, 516, Gojan 1-dong, Danwon-gu, Ansan 425-707, Korea. Tel: 82-31-412-5295, Fax: 82-31-412-5294, E-mail: anejhkim@korea.ac.kr

(c) This is an open-access article distributed under the terms of the Creative Commons Attribution Non-Commercial License (http:// creativecommons.org/licenses/by-nc/3.0/), which permits unrestricted non-commercial use, distribution, and reproduction in any medium, provided the original work is properly cited. 
between hospital admission and surgery. There has been a need to develop more sophisticated methods to improve patient preparation. The role of media, such as videos and printed materials about anesthesia, has been the subject of many randomized controlled trials and showed the superiority of using media to the interview alone to achieve the patient's satisfaction and understanding and reduce the patient's anxiety during the perioperative period $[6,7]$.

The outcome of their study [3] raises several questions for future investigations. Does increased interview time lead to increased patient satisfaction and decreased anxiety? Should anesthesia programs devote more time during residency to teaching effective communication skills with patients? Are there differences in the techniques used by residents and senior anesthesiologists to obtain needed information, and which techniques are more effective? Future trials are needed to obtain more effective and useful methods in the preoperative evaluation and interview.

\section{References}

1. Egbert LD, Battit G, Turndorf H, Beecher HK. The value of the pre- operative visit by an anesthetist. A study of doctor-patient rapport. JAMA 1963; 185: 553-5.

2. Kindler CH, Szirt L, Sommer D, Hausler R, Langewitz W. A quantitative analysis of anaesthetist-patient communication during the pre-operative visit. Anaesthesia 2005; 60: 53-9.

3. Kim DK, Lee SN, Kim DC, Lee JW, Ko SH, Lee SK, et al. The preanesthetic interview by anesthesiology residents: analysis of time and content. Korea J Anesthesiol 2012; 62: 220-4.

4. Harms C, Young JR, Amsler F, Zettler C, Scheidegger D, Kindler CH. Improving anaesthetists' communication skills. Anaesthesia 2004; 59: 166-72.

5. Tsen LC, Segal S, Pothier M, Bader AM. Survey of residency training in preoperative evaluation. Anesthesiology 2000; 93: 1134-7.

6. Snyder-Ramos SA, Seintsch H, Bottiger BW, Motsch J, Martin E, Bauer M. Patient satisfaction and information gain after the preanesthetic visit: a comparison of face-to-face interview, brochure, and video. Anesth Analg 2005; 100: 1753-8.

7. Salzwedel C, Petersen C, Blanc I, Koch U, Goetz AE, Schuster M. The effect of detailed, video-assisted anesthesia risk education on patient anxiety and the duration of the preanesthetic interview: a randomized controlled trial. Anesth Analg 2008; 106: 202-9. 